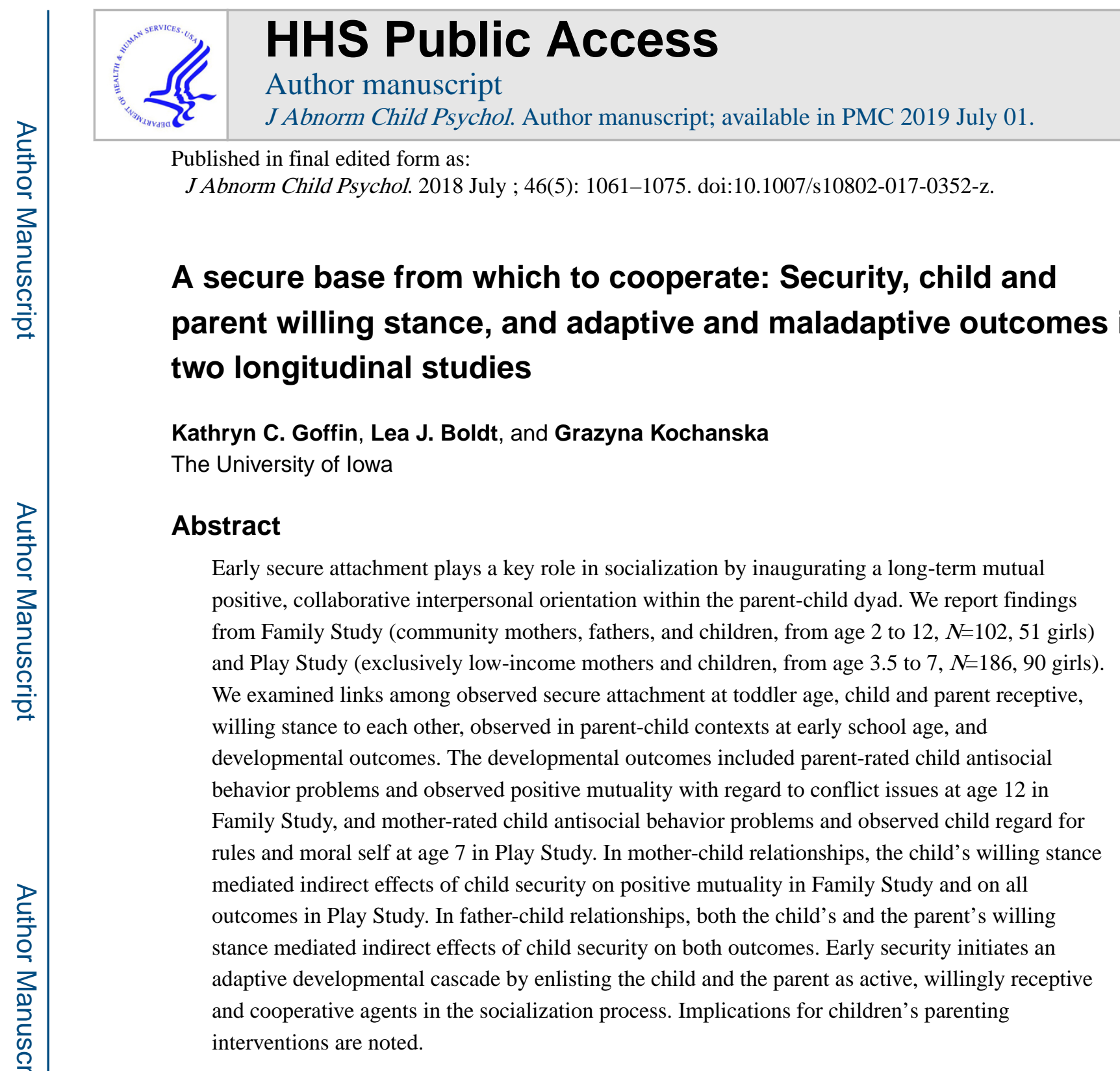

\title{
Keywords
}

Parent-child attachment; child and parent willing stance; socialization processes

\begin{abstract}
Traditionally, parent-child socialization has been portrayed as a vaguely adversarial process, particularly in research on origins of developmental pathways leading to children's disruptive behavior problems. Increasingly complex and methodologically sophisticated bidirectional transactional models have depicted the parent and the child as active contributors to mutually coercive parent-child dynamics evolving within the dyad (e.g., Bradley \& Corwyn, 2013; Dishion \& Patterson, 2006; Lipscomb et al., 2011; Lorber \&
\end{abstract}

\footnotetext{
Correspondence concerning this article should be addressed to Kathryn C. Goffin, Department of Psychological and Brain Sciences, The University of Iowa, Iowa City, IA, 52242. kathryn-goffin@uiowa.edu.

Kathryn C. Goffin, Department of Psychological and Brain Sciences, The University of Iowa; Lea J. Boldt, Department of

Psychological and Brain Sciences, The University of Iowa; Grazyna Kochanska, Department of Psychological and Brain Sciences,

The University of Iowa.

The authors declare that they have no conflict of interest.
} 
Egeland, 2011; Pardini, 2008; Patterson, DeBaryshe, \& Ramsey, 1989; Pettit \& Arsiwalla, 2008; Reid \& Patterson, 1989; Shaw \& Bell, 1993; Smith et al., 2014). That research has substantially enhanced our understanding of the origins of antisocial, disruptive trajectories and has informed evidence-based interventions.

One limitation of that approach has been a focus on mostly negative and adversarial processes: The child's role is generally depicted in terms of difficult temperament, aversive noncompliance, resistance, opposition, insensitivity to punishment, and other attributes that elicit coercive, harsh parenting (Bates, Schermerhorn, \& Petersen, 2012; Dadds \& Salmon, 2003; Hawes, Dadds, Frost, \& Hasking, 2011). As well, the parent is typically depicted as an adversarial, harsh disciplinarian. Over time, the evolving coercive transactions lead to outcomes such as children's conduct problems, poor internalization and rejection of parents' values, disregard for conduct rules, growing resentment and conflict in the parent-child relationship-understandingly, also described in mostly negative terms.

Such portrayal of socialization, although accurate, is incomplete. Over the last two decades, developmental researchers increasingly have come to appreciate the role of "positive socialization forces" that can serve as protective factors, lowering the risk for antisocial problems (Gardner, Burton, \& Klimes, 2006; Kochanska, Koenig, Barry, Kim, \& Yoon, 2010a; Kochanska et al., 2010b; Pardini, Waller, \& Hawes, 2015; Pasalich, Dadds, Hawes, \& Brennan, 2012; Shaw, 2003). The new models depict the child and the parent as potentially cooperative partners, actively engaging in socialization, which can become a reciprocal, collaborative enterprise.

Attachment theory has been key in fueling interest in such models (Hoeve et al., 2012; Shaver, Mikulincer, Gross, Stern, \& Cassidy, 2016; van IJzendoorn, 1997). Originally, Bowlby (1969/1982/1973) conceptualized the main function of attachment as assuring the infant's proximity to the caregiver, and, consequently, providing the child with protection and comfort during stress, distress, or threat, and a secure base from which to explore in the absence of threat. Research has documented important implications of such biobehavioral security: Children's trust in a safe haven and the caregiver's availability, confidence in protection and comfort when needed, effective behavioral and physiological regulation of emotion, and openness to exploration (Cassidy, 2008; Thompson, 2016).

Secure attachment soon began to be construed more broadly, as inaugurating a long-term mutual, willing, receptive, and cooperative orientation between the child and the parent. Such conceptualization converged with reciprocity theories in developmental psychology (Maccoby, 1992; Parpal \& Maccoby, 1985), the concept of a communal relationship in social psychology (Clark, 1984), and the notion of the "goal-corrected partnership" in attachment theory (Bowlby, 1969/1982; Marvin, Britner, \& Russell, 2016).

Evidence has supported the role of early secure attachment for the child's willing cooperation with the parent. As Waters, Kondo-Ikemura, Posada, and Richters (1990) proposed, having established a secure base, the child progresses toward a "positive orientation toward parental socialization goals and internalization of family values in early childhood" (p. 229). Classic and current research has shown secure children to be more 
likely to internalize caregivers' rules (Bretherton, Golby, \& Cho, 1997; Kochanska, Aksan, \& Carlson, 2005; Laible \& Thompson, 2000; Londerville \& Main, 1981; Matas, Arend, \& Sroufe, 1978; Thompson, 2015; van IJzendoorn, 1997). Research has also supported longterm paths, in which security launches a socialization cascade by promoting the child's eager, receptive attitude toward the parent's influence (Kochanska, Kim, \& Boldt, 2015). Such attitude, labeled here as "a willing, receptive stance," leads to positive socialization outcomes, particularly the child's embrace of parental values, regard for rules, and an overall positive parent-child relationship quality.

Still, substantial gaps in our understanding remain. If security is indeed a foundation of a mutual, dyadic cooperative orientation, we would expect that it may also lead to the parent's future positive, willing stance toward the child. Consistent with the concepts of goalcorrected partnership in attachment theory and reciprocity in relationship research, we might expect that as the child eagerly cooperates with the parent's demands and requests, the parent is likely also to become more accommodating toward the child. Although such a cascade has been proposed (Thompson, 2006), effects of early security on the parent's willingness to cooperate with the child have very rarely been studied.

In the current work, we examine and formally test a model of mechanisms that may link early security and future developmental outcomes. We posit that both the child's willing stance toward the parent and the parent's willing stance toward the child may serve as such mechanisms. Consequently, we test a model that proposes two mediational mechanisms to account for the links between toddler-age security and future outcomes-the child's and the parent's future willing stance toward each other, assessed approximately 3.5-4.5 years after the assessment of security. We expected to replicate the significant path from child security to child willing stance to future outcomes, found in past research. Given the dearth of research on effects of security on the parent's willing stance, the examination of the path from security to parent willing stance to future developmental outcomes was exploratory.

We programmatically embrace the recent emphasis on the importance of replicability in behavioral sciences. This work entails a substantial replication across samples and over time, by bringing together two large studies-Family Study and Play Study. The new elements include the extension of past work to include both the child's and the parent's willing stance, additional developmental periods in the developmental cascade, and new studied outcomes.

Family Study followed community families (infants, mothers, and fathers) from infancy to early adolescence. The earlier work examined the cascade from security at age 2 , to children's willing stance, observed at ages $3,4.5$, and 5.5, to outcomes at age 10 (children's antisocial behavior problems, their obligation to obey and trust in the parents, and positive parenting, Kochanska et al., 2015). The current work extends the studied cascade from early security to willing stance-now assessed for both the child and the parent-observed at age 6.5 to maladaptive and adaptive outcomes at age 12 . We assess antisocial behavior problems, as well as a new outcome, particularly relevant in adolescence-parent-child positive mutuality observed in the context of negotiating issues identified as sources of conflict. 
Play Study involved exclusively low-income mothers of toddlers, who entered at age 2.5 and were then randomized to a 3-month parenting intervention (child-oriented play or play-asusual group, Kochanska, Kim, Boldt, \& Nordling, 2013). Earlier work (Kochanska, Kim, \& Boldt, 2013) revealed that adversity in the mothers' lives undermined their responsiveness; this was associated with children's diminished willing stance toward the mothers (all assessed at baseline, at age 2.5). Diminished willing stance led to externalizing behavior problems at age 3.5 (the two groups were combined, given the lack of differences due to group assignment). The current work examines child attachment at age 3.5 as a predictor of the child's and the mother's willing stance and child maladaptive and adaptive outcomes (all at age 7): child antisocial behavior problems, regard for rules of conduct, and moral self (self-concept with regard to internalization of rules).

To bolster replicability, a substantial subset of methods purposely included measures fully comparable across the two studies. In both studies, trained observers assessed children's early security, using Attachment Q-Set (AQS, Waters, 1987). Children's willing stance was observed in three parent-child contexts: a discourse about past misbehavior, teaching tasks, and naturalistic interactions. Parents' willing stance was observed during naturalistic interactive situations. Children's antisocial behavior problems were assessed using established age-appropriate companion measures. The observed outcome measures were tailored to children's ages (early adolescence in Family Study, early school age in Play Study). In Family Study, the parent and child took part in a paradigm, adapted from attachment-informed studies of adolescents, in which they discussed issues that most often elicited conflicts in their relationship (Allen et al., 2003; Allen, McElhaney, Kuperminc, \& Jodl, 2004; Sroufe, Egeland, Carlson, \& Collins, 2005). In Play Study, we observed child regard for rules and moral self, using methods established in past work (e.g., Kochanska et al., 2010a).

Both studies examined a model that proposed a presence of two mediational mechanisms accounting for links between toddler-age security and future outcomes: The child's and the parent's future willing stance toward each other. We implemented PROCESS (Hayes, 2013), a flexible computational tool designed to test various forms of mediation. The judgment about the presence of an indirect effect relies on the bootstrap confidence interval (CI). The bootstrapping approach is preferred for inference regarding indirect effects because the sampling distribution of indirect effects is not assumed to be normal (MacKinnon, Lockwood, \& Williams, 2004; Preacher \& Hayes, 2004). Because PROCESS uses listwise deletion, we first imputed missing data in SPSS, using a regression-based method. Consequently, the analyses take advantage of the entire sample.

To strengthen our inferences, we controlled for a number of earlier covariates (Cole \& Maxwell, 2003; Hoyle \& Robinson, 2003). In Family Study, for each outcome at age 12, we covaried the earlier measure, obtained at age 6.5 , concurrent to the mediators, using an analogous data collection method (i.e., parent-rated, observed). We also covaried the earlier observed measures of the mediators (the child's and the parent's willing stance toward each other), collected in infancy. In Play Study, we controlled for the antecedent measures of each outcome and of mother and child willing stance, obtained at baseline (age 2.5), and for group assignment. Child gender was covaried in all analyses. 
In both studies, multiple teams coded behavioral data. Reliability (kappas, intraclass correlations, ICCs) was established on 15-20\% of cases, followed by realignments to prevent coder drift. Data were aggregated at many levels to create robust constructs (Rushton, Brainerd, \& Pressley, 1983).

\section{Family Study}

\section{Method}

Participants-Two-parent community families of typically developing infants $(N=102$, almost all born in 2001), recruited by flyers and ads in a Midwestern college town and surrounding communities, volunteered for the study. At entry, families ranged in their annual income (8\% earned less than $\$ 20,000,17 \% \$ 20,000-\$ 40,000,26 \% \$ 40,000-\$ 60,000$, and $49 \%$ over $\$ 60,000)$ and education ( $25 \%$ of mothers and $30 \%$ of fathers had no more than a high school education, $54 \%$ of mothers and $51 \%$ of fathers had an associate or bachelor's degree, and $21 \%$ of mothers and $20 \%$ of fathers had postgraduate education). Regarding ethnicity, $90 \%$ of mothers and $84 \%$ of fathers were White, $3 \%$ of mothers and $8 \%$ of fathers were Hispanic, $2 \%$ of mothers and 3\% of fathers were African American, $1 \%$ of mothers and 3\% of fathers were Asian, $1 \%$ of mothers were Pacific Islander, and 3\% of mothers and $2 \%$ of fathers were non-White other. In $20 \%$ of families, one or both parents were nonWhite.

Overview of design-This article reports data from three times: at 25 months (age 2, $N=$ $100)$, at 80 months (age $6.5, N=90)$ and at age $12(N=79)$. Additionally, infancy measures of child and parent responsiveness (at 7 months) were used as covariates. At each time, each child completed two video-recorded 2.5-3-hr sessions in the laboratory (in infancy, at home), one with each parent, conducted by a female experimenter (E). At age 2, child security with each parent was assessed, using AQS (Waters, 1987; Waters \& Deane, 1985). At age 6.5, the child's willing stance toward each parent was observed in three contexts: discourse about child previous misbehavior, a teaching task, and a set of six scripted, naturalistic interactive situations (e.g., snack, play); the parent's willing stance was observed only in the latter set of six naturalistic situations. At age 12, we assessed maladaptive and adaptive outcome: Parent-rated antisocial behavior problems and observed positive mutuality in paradigms designed to elicit conflicts and disagreement in the parent-child dyad (available measures of the outcomes, obtained at age 6.5, were used as covariates). Complete descriptive data for all constructs are in Table 1 in Online Supplemental Materials.

\section{Measures}

Children's attachment security, age 2 years: Highly trained coders, who observed the child and parent during the entire 2.5-hr laboratory session in psychologically diverse contexts, performed AQS (Boldt, Kochanska, Yoon, \& Nordling, 2014). The coding and data reduction were conducted according to standard guidelines (90 cards sorted into nine 10card piles ranging from $1=$ most uncharacteristic to $9=$ most characteristic, each sort correlated with the prototypical "secure child" criterion sort). Inter-observer reliability, ICC, was .85 . 


\section{The child's willing stance, age 6.5 years}

Discourse about child misbehavior: Observed contexts, coding, reliability, and data

aggregation: Parent-child dyads discussed, for up to $5 \mathrm{~min}$, one child misbehavior from the previous week (chosen by the parent from a diary kept for a week, Kochanska et al., 2015). The parent prompted the child to recall the event, asked how he or she and or others had felt, and discussed consequences (a discourse about good behavior followed, but was not coded). Discourse was coded for each 30-s segment (maximum of 10). The scores were tallied and divided by the number of segments.

Coders rated child willingness to engage in discourse as $1=$ reluctant/unwilling (child clearly indicated that the conversation was unwelcome; actively refused to talk, attempted to change the topic, denied or gave a false account of the event, denied the behavior was wrong), $2=$ passive engagement/passively unwilling (passively engaged; silent, pretended not to hear, delayed responding, said "don't know" or “don't remember," replied in monosyllables), or 3 = cooperative/willing (contributed actively and easily, elaborated, agreed the behavior was wrong). Reliability, ICCs, ranged from .82 to .88 .

Coders also rated child physical avoidance (moving away, turning away, or struggling to get away from the parent; avoiding eye contact; playing with own clothing or other objects; silly behaviors to avoid the conversation, such as singing, tickling the parent, or standing on one's head), as $1=$ not present/minimal, $2=$ low to moderate, or $3=$ intense. Reliability, ICCs, ranged from .90 to .91 . The two codes were standardized and aggregated, with physical avoidance reversed, into a score of child willing stance in discourse.

Teaching task: Observed contexts, coding, reliability, and data aggregation: The parent demonstrated assembly of a frog or a bear, using craft materials provided, for approximately $3 \mathrm{~min}$, and then instructed the child to imitate by saying "Now you do it" for approximately 7 min (Kochanska et al., 2010b). For each 1-min segment, coders rated child responsive imitation as low, fair, good, or excellent, integrating behaviors and affect. The behaviors included child postural orientation (e.g., eye contact, physical proximity, attention) and contingent response (e.g., watches demonstration when instructed to by the parent, turns to the parent's voice); affect included facial expressions, vocalizations, etc. Reliability, ICC, was .83. Each score was tallied. The tallies were weighted: low were multiplied by -2 , fair by -1 , good by +1 , and excellent by +2 . Those figures were added and divided by the number of coded segments.

Responsiveness in naturalistic interactions: Observed contexts, coding, reliability, and data aggregation: Each parent-child dyad participated in six situations (total of $60 \mathrm{~min}$ ) designed to resemble typical naturalistic interactions (e.g., snack, parent busy, play, toy cleanup, Kochanska et al., 2010b).

Child responsiveness was rated for each situation, from $1=$ highly unresponsive to $7=$ highly responsive. The rating reflected the child's acceptance of, cooperation with, and sensitivity to the parent's social cues and overtures, and the probability of pleasing the parent. Reliability, ICC, was .92. The scores cohered across the six observed situations; Cronbach alphas for mother- and father-child dyads were .81 and .85 , respectively. Thus, the 
scores were averaged across all contexts into the child's overall responsiveness score toward each parent.

Overall measure of child willing stance: The three scores-cooperation in discourse, responsive imitation in the teaching task, and responsiveness in naturalistic interactionswere aggregated into an overall composite of willing stance toward each parent (having standardized the latter two scores). Cronbach's alpha for mother- and father-child dyads were .62 and .63 .

The parent's willing stance, age 6.5 years: For the parent, responsiveness was also rated in the same six naturalistic interactive situations as for the child, from $1=$ highly unresponsive to 7 = highly responsive (Kochanska et al., 2013a). The rating, adapted from Ainsworth, Bell, and Stayton (1971), integrated sensitivity-insensitivity to the child's cues, cooperationinterference, and acceptance-rejection. Reliability, ICC, was .98. The scores cohered across the six observed situations (Cronbach alphas for mother- and father-child dyads, .85 and .78, respectively), and were averaged across all situations into the parent's overall responsiveness score (willing stance) toward the child.

\section{Socialization outcomes, age 12 years}

Parent-reported children's antisocial behavior problems: Both parents completed the Adolescent Symptoms Inventory-4R (ASI-4R, Gadow \& Sprafkin, 2008), an established, DSM-IV-TR-compatible instrument (American Psychiatric Association, 2000). We computed the sum of oppositional defiant disorder, conduct disorder, and antisocial personality disorder (total 28 items), with each rated for severity, from $0=$ never to $3=$ very often. Parents also completed the Health Behavior Questionnaire (HBQ, Essex et al., 2002). We used the Overt Aggression scale (4 items, averaged), rated from $1=$ never/not true to $3=$ often/very true. The ASI-4R and HBQ scores correlated, $r(78)=.68, p<.001$ for mothers and $r(75)=.55, p<.001$ for fathers; they were standardized and averaged into child overall antisocial behavior problems score.

Positive mutuality regarding conflicts: Observed contexts, coding, reliability, and data aggregation: Each parent-child dyad discussed two different "hot button" issues on which they often disagreed (e.g., chores, friends; 4 min each). Typically, the parent chose one issue and the child chose the other. For each issue, coders rated the dyad's positive mutuality, from 1 = very untrue of dyad; very low mutuality, very poor working relationship, to $5=$ very true of dyad; very high mutuality, excellent working relationship. The rating integrated coordination, harmonious communication, mutual cooperation, and positive emotional ambiance. Reliabilities, ICC, ranged from .80 to .88 . The final score was the mean of the two discussions, $I(73)=.69, p<.001$ for mothers and $I(71)=.63, p<.001$ fathers.

Covariates: Two measures observed in infancy were considered early antecedents of the mediators at age 6.5 (child and parent willing stance). Observed child responsiveness to the parent and the parent's responsiveness to the child had been coded during approximately 45 min of naturalistic, but scripted interactions in several contexts (e.g., play, snack, parent busy, caregiving), using the age-appropriate versions of the responsiveness coding systems 
used also at age 6.5, and aggregated across the contexts. Those scores were covaried in all analyses (for the respective parent). Child gender was also covaried in all analyses.

Two measures obtained at age 6.5 were considered antecedents of the outcomes at age 12 . Mother- and father-rated scores of child externalizing problems were created in the manner parallel to age 12, using Child Symptom Inventory-4 (CSI-4; Gadow \& Sprafkin, 2002), a companion instrument for younger ages, and HBQ. Parent-child positive mutuality was observed in a 10-min context during which the dyad sat at a table, had a snack, and engaged in a conversation.

\section{Results}

Preliminary analyses-We analyzed the pattern of missing data using Little's MCAR test (Little, 1988). The results indicated that the data were missing at random, $\chi^{2}(222)=$ $253.39, p=.073$. The preliminary analyses examined correlations among the variables in mother-child and father-child dyads (see Table 2 in Online Supplemental Materials). In mother-child dyads, the correlations were generally modest and in expected directions. Security at age 2 was positively associated with both children's and mothers' willing stance at age 6.5 and with positive mother-child mutuality regarding conflicts at age 12 , and negatively associated with mother-rated child antisocial behavior problems at age 12 . Child willing stance was positively, albeit modestly, associated with mother concurrent willing stance at age 6.5 and with mutuality at age 12 and negatively associated with antisocial behavior problems at age 12 . The two outcomes at age 12 were negatively related. The two covariates at age 6.5 , mother-rated child antisocial behavior problems and observed mutuality, predicted the respective outcomes at age 12. Mother responsiveness in infancy (a covariate) predicted her willing stance at age 6.5 and child security at age 2 . Child responsiveness in infancy (a covariate) predicted security at age 2 .

In father-child dyads, the pattern of correlations was similar. Security at age 2 was positively associated with both child and father willing stance at age 6.5 and with positive father-child mutuality regarding conflicts at age 12 , and negatively associated with father-rated child antisocial behavior problems at age 12. Child willing stance was associated with positive mutuality, and negatively with antisocial behavior problems at age 12 , but unrelated with the father's concurrent willing stance. The two outcomes at age 12 were negatively associated. The two covariates at age 6.5, father-rated child antisocial behavior problems and observed mutuality, predicted the respective outcomes at age 12. Father responsiveness in infancy (a covariate) predicted his willing stance at age 6.5 and child security at age 2 . Child responsiveness in infancy (a covariate) predicted security at age 2 .

\section{The testing of the mediational pathways from the child's early attachment security to the future child and parent willing stance toward each other to the developmental outcomes-For each of the two outcomes, child security at age 2 was} modeled as the independent variable, child and parent willing stance to each other at age 6.5 were modeled as the mediators, and child gender and the respective child and parent responsiveness in infancy were the covariates. Parent-rated child antisocial behavior at age 6.5 was covaried in the analyses of antisocial behavior problems, and observed positive 
mutuality in the respective parent-infant interactions at 6.5 was covaried in the analyses of positive mutuality. Findings from PROCESS (Hayes, 2013) are in Figures 1 and 2 (motherchild and father-child dyads, respectively).

Mother-child dyads: The paths to mother-rated child antisocial behavior problems and to positive mother-child mutuality regarding conflicts at age 12 (Figure 1): In the model predicting mother-rated child antisocial behavior at age 12 , only the paths from security at age 2 to the child's and the mother's willing stance at age 6.5 were significant. There were no other significant effects.

In the model predicting mother-child positive mutuality at age 12 , there was a significant indirect effect of security, mediated by the child's willing stance toward the mother at age 6.5. The mother's willing stance toward the child did not mediate the links between security and positive mutuality.

Father-child dyads: The paths to father-rated child antisocial behavior problems and to positive father-child mutuality regarding conflicts at age 12 (Figure 2): In both models, one with the father-rated antisocial behavior at age 12 and one with positive mutuality at age 12, the paths from security at age 2 to both the child's and the father's willing stance at age 6.5 were significant. As well, the indirect effects-from security to child willing stance to antisocial behavior and/or to positive mutuality and from security to father willing stance to antisocial behavior and/or to positive mutuality-were all significant. In addition to the indirect effects, security had a significant direct effect on father-child mutuality at age 12 .

\section{Discussion}

The key question addressed in our models was whether early security provides a foundation for a positive parent-child trajectory up to early adolescence, marked by few antisocial conduct problems and high positive mutuality while negotiating typical conflict issues. Further, we proposed that such positive effects would be mediated by the child's and the parent's willing stance toward each other, assessed in early school age. In other words, we proposed that security exerts its long-term positive effects by engendering a willing stance in both the child and the parent, and engaging them both in the common, collaborative enterprise of socialization.

Our findings for fathers and children fit such conceptual model very well. Early father-child security, established in toddler age, appeared to promote both the child's and the parent's willing, cooperative stance toward each other in early school age. That willing stance, the child's and the father's, then predicted fewer antisocial problems and more positive mutuality at age 12. Although our design was not experimental, and inferences about causality have to be made cautiously, we controlled for the measures of outcomes assessed concurrently with the mediators, and for antecedents of the mediators, assessed in infancy. Those features of the design strengthen our interpretation of the causal pathway from early security to the outcomes in early adolescence, beyond and above the continuity of the assessed constructs. 
For mothers and children, the proposed sequence from security to willing stance to future outcomes was significant only in the model predicting positive mutuality at age 12 , and not in the model predicting antisocial behavior. The indirect effect of security on mutuality was mediated by the child's willing stance; the mother's willing stance was not a significant mediator. The absence of significant indirect effects in the model predicting child antisocial behavior at age 12 was likely due to the very robust effect of a covariate-child antisocial problems at age 6.5. That measure correlated strongly with the outcome, $r(78)=.68, p<$. 001 .

This study makes several contributions. First, we have enhanced our understanding of the child's role as an active positive agent in socialization, rather than an agent of resistance, noncompliance, or difficulty. Second, we demonstrated that the child's willing stance can be reliably coded in diverse observed parent-child socialization contexts: a discourse about past transgressions, a teaching task calling for imitation, and naturalistic interactive situations. Third, three out of four models supported the conceptually proposed path from early security to child willing stance to future developmental outcomes in early adolescence. Additionally, two of those models (both involving father-child relationships) revealed also the proposed significant paths from security to the father's willing stance to future outcomes. Fourth, in the model predicting father-child dyads' positive mutuality, likely due to the relational quality of this outcome, security had both direct and indirect effects (Thompson, 2006, 2016).

\section{Play Study}

\section{Method}

Participants-Participants were 186 mother-child dyads, with children aged 30 months (age 2.5, born between 2003 and 2008), who responded to flyers distributed in the community, targeting areas frequented by low-income families (e.g., Head Start, subsidized housing, Women, Infants, and Children program offices, thrift stores). Mothers had to qualify for or receive financial assistance from a federal, state, or faith-based agency, or Earned Income Tax Credit; the child had to have no known major health problems; and mothers had to have the ability to speak English while being observed in the study. The average annual family income was $\$ 20,385, S D=\$ 13,010 ; 5 \%$ of the mothers did not have a high school diploma, 50\% had high school diploma or GED, and $45 \%$ had an associate, BA, or technical degree. Regarding ethnicity, $11 \%$ were Hispanic (40\% of those considered themselves White) and $87 \%$ not Hispanic (2\% “other"); regarding race, $73 \%$ were White, $15 \%$ African American, 2\% Asian, 2\% American Indian, and 8\% more than one race or unreported. Fifty-four percent of the mothers were married, 31\% single or divorced, $13 \%$ cohabitated, and $2 \%$ in other arrangements.

Overview of design-Each mother-child dyad was observed in a 3.5-hour laboratory session when children where 40 months (age 3.5, N=162) and again in a 3-hour laboratory session when they were 86 months (age 7, $N=118$ ). Previous assessments were not used in this article (baseline at 2.5 years, a 3-month intervention in two randomized groups, and immediate post-intervention assessment), except for the covariates obtained at baseline. We 
present results for the entire sample, as there was only one group difference attributable to the intervention, for mother responsiveness to the child at age 7, the measure of maternal willing stance (group assignment was controlled in the analyses as an added safeguard). Female experimenters (Es) conducted the video-recorder sessions. Observers coded child attachment at 3.5 years, using AQS, parallel to Family Study, and child and mother willing stance toward each other at age 7, in the same three contexts as in Family Study. Child outcomes at age 7 were mother-rated child antisocial behavior problems and observed regard for rules and moral self. Descriptive data for all constructs are in Table 1 in Online Supplemental Materials.

\section{Measures}

Attachment security, age 3.5 years: The procedure was the same as in Family Study. A trained coder completed AQS for each mother-child dyad, based on the observation of the entire session. Inter-observer reliability, ICC was .88.

\section{The child's willing stance, age 7 years}

Discourse about child misbehavior: Observed contexts, coding, reliability, and data aggregation: As in Family Study, each mother-child dyad discussed one child misbehavior from the past week, and the coding of child and mother behavior and data aggregation paralleled those in Family Study. Reliability, ICC, was 1.00 both for child willingness to engage and for physical avoidance. Willingness to engage and reversed avoidance were standardized and aggregated.

Teaching task: Observed contexts, coding, reliability, and data aggregation: Each motherchild dyad completed the same teaching task as in Family Study, assembling a bear. The duration, instructions, coding, and data aggregation were the same as in Family Study. Reliability, ICCs, ranged from .80 to .82 for child responsive imitation.

\section{Responsiveness in naturalistic interactions: Observed contexts, coding, reliability, and} data aggregation: As in Family Study, each dyad interacted in six naturalistic, scripted situations (e.g., snack, play; total of 50 minutes). Coding and data aggregation were parallel to Family Study. Reliability, ICCs, ranged from .90 to .95 . Cronbach's alpha for the codes across the situations was .78.

Overall measure of child willing stance: The overall composite was created in the manner parallel to Family Study. Cronbach's alpha was .61.

The mother's willing stance, age 7 years: As in Family Study, the mother's responsiveness observed in the same set of six naturalistic situations, averaged across the situations, was the measure of her willing stance. Reliability, ICCs, ranged from .81 to .92. Cronbach's alpha for the codes across the situations was .75 .

\section{Socialization outcomes, age 7 years}

Mother-reported antisocial behavior problems: Mothers completed the CSI—4 (Gadow \& Sprafkin, 2002). We computed the sum of oppositional defiant disorder and conduct disorder 
(23 items), with each rated for severity, from $0=$ never to $3=$ very often. Mothers also completed the 4-item HBQ Overt Aggression scale. The CSI-4 and HBQ scores correlated, $r(118)=.56, p<.001$, were standardized and averaged into the overall antisocial behavior score.

Regard for rules: Internalization of maternal prohibition, observed context, coding, reliability, and data aggregation: At the outset of the laboratory session, the mother prohibited the child from touching attractive objects on a low shelf and enforced the prohibition throughout the session. Near the end of the session, she repeated the prohibition and left the room. The child was then given a boring sorting task, directly in front of the shelf ( $8 \mathrm{~min}$ ). For each 5-s segment, we coded child behavior as: other activity (e.g., snacking, walking), engaged in sorting, looking at the forbidden objects without touching, self-correcting (i.e., raising hand to touch the objects and withdrawing), gently touching the objects, or violating prohibition (i.e., playing with the objects). Reliability, kappas, ranged . 91-.95. Latencies to first look, touch, or violation were also coded. Reliability, ICC, ranged . 95-1.00. The relative scores (tallies for each behavior divided by number of segments) and latencies were submitted to principal components analysis. The first factor reflected internalization of maternal prohibition (eigenvalue $3.69,32 \%$ of variance). Gentle touch and violations of prohibition loaded negatively, and latencies to touch and to violation loaded positively, replicating several previous studies (e.g., Kochanska, Coy, \& Murray, 2001). This factor score was the measure of internalization of prohibition.

Regard for rules: Rule violations in a game, observed context, coding, reliability, and data aggregation: The $\mathrm{E}$ first described the rules (which made the task essentially impossible), and asked the child not to "cheat" in a friendly but serious manner. The game involved completing a puzzle placed behind a cloth in a box with a clear back, without lifting the cloth, pulling a piece of the puzzle out of box, or looking through the clear back (Eisenberg et al., 2000; Kochanska \& Kim, 2014). The child was left alone, to play a puzzle box game for $3 \mathrm{~min}$, and expected to win a prize. Child behaviors that violated the rules were coded for every 3-s segment. The behaviors were coded as not participating in game, fully rulecompliant, breaking one rule only, or breaking more than one rule (reliability, kappas, .9095). The latencies to rule violations were also coded (ICCs .87-1.00). The codes were standardized and then aggregated into the final score for rule violations. Cronbach's alpha was .71 .

Regard for rules: Overall composite: Internalization of maternal prohibition and (reversed) rule violations in the puzzle box game correlated, $r(114)=.30, p=.001$, and were averaged into an overall composite of regard for rules.

Moral self: Observed context, coding, reliability, and data aggregation: E engaged the child in a puppet interview. The puppets, matched to child gender, elicited self-descriptions in 31 statements about guilt, empathy, and internalization of rules. For each, one puppet described the self as anchoring the high end and the other as anchoring the low end (e.g., "When I break something, I try to hide it so no one finds out;" "When I break something, I tell someone about it right away."). The child then pointed to the puppet most like him or 
her. Child answer was coded as 0 (low end), as 2 (high end), and as 1 (child appeared ambivalent, endorsed both options, e.g., "sometimes like her and sometimes like her"). The final score was the average of all items.

Early covariates, age 2.5 years: Measures obtained at the baseline were used as covariates. Two measures were antecedents of the outcomes at age 7. Mothers' ratings of children's externalizing behavior problems in Infant-Toddler Social and Emotional Assessment (ITSEA, Carter, Briggs-Gowan, Jones, \& Little, 2003); the mean of 24 items encompassing impulsivity, aggression/defiance, and peer aggression were covaried in the analyses of antisocial behavior problems at age 7. The composite of observed internalization of maternal prohibition and (reversed) rule violations in a game, both assessed in paradigms fully analogous to those at age 7 , was covaried in the analyses of regard for rules at age 7 . There was no measure of moral self prior to security assessment.

Two measures parallel to Family Study, obtained at baseline, were seen as the antecedents of the mediators (child and mother willing stance at age 7) and covaried in all analyses. Child responsiveness to the mother and mother responsiveness to the child were observed in interactions in seven scripted contexts at baseline (62 minutes), and coded using ageappropriate versions of the coding systems used at age 7 . Child gender and the dyad's group assignment were also covaried in all analyses.

\section{Results}

Preliminary analyses-Little's MCAR test indicated that data were not missing at random, $\chi^{2}(18)=48.16, p<.001$. Families who did not return at age 7 were more likely to be African-American, be less educated, have a male child participant, and score lower on attachment security. In the preliminary analyses, we examined the correlations among the variables (see Table 3 in Online Supplemental Materials). The correlations were mostly similar in size and directions to Family Study. Security at age 3.5 positively related to child willing stance and to regard for rules at age 7, and negatively-to antisocial behavior problems at age 7 . Mother and child willing stance were positively, although modestly, correlated. Child willing stance was associated negatively with his or her behavior problems and positively with regard for rules and moral self. The covariates at age 2.5 related to several later measures. Externalizing behavior problems at age 2.5 negatively related to security at age 3.5 and child willing stance at age 7 and positively to antisocial behavior problems at age 7 . Regard for rules at age 2.5 positively related to security and child willing stance. Child and mother responsiveness to each other at age 2.5 were positively related to, respectively, child and mother willing stance to each other at age 7.

\section{The testing of the mediational pathways from child's early attachment security to the child and mother future willing stance toward each other to developmental outcomes-For each of the three outcomes, child security at age 3.5 was modeled as the independent variable, child and mother willing stance to each other at age 7 were both modeled as the mediators, and child gender, the respective child and mother responsiveness at baseline (age 2.5), and group assignment were the covariates. Additionally, maternal baseline ratings of child externalizing behavior problems (ITSEA)}


were covaried in the analyses of antisocial behavior problems at age 7, and child baseline observed regard for rules was covaried in the analyses of regard for rules at age 7 . The findings from PROCESS (Hayes, 2013) are in Figure 3.

The paths to mother-rated child antisocial behavior problems, child regard for rules, and child moral self at age 7: The path from security at age 3.5 to children's willing stance at age 7 was significant in all models, but the path from security to mothers' willing stance was not. For all three outcomes, the indirect effects of security, mediated by the child's willing stance toward the mother, were present. By contrast, there were no indirect effects via the mother's willing stance. Security had no direct effects on any of the outcomes in the final models.

\section{Discussion}

The findings in this high-risk, exclusively low-income, diverse sample of mothers and toddlers, essentially replicated those obtained in low-risk, two-parent community families. The child's security with the mother, assessed, as in Family Study, by trained observers, predicted few behavior problems and positive outcomes at age 7 , and the relations were mediated by the child's willing stance, assessed with methods parallel to Family Study.

There was a predicted indirect effect of security for children's antisocial behavior problems. Recall that in Family Study, due to a strong effect of the earlier measure, we failed to find the significant indirect path from security to mother-reported antisocial problems at age 12, although we found it for father-reported problems. In Play Study, however, the correlation between earlier measure of antisocial behavior (a covariate) and the later measure was moderate, and thus the indirect effect was significant. There were also predicted indirect effects of security on the observed measures of children's regard for conduct rules and the moral self at age 7. Also parallel to Family Study, we failed to find mediation through the mother's willing stance toward the child. Note that fathers did not participate in Play Study. Consequently, we do not know if the indirect effects from security to father willing stance to child outcomes would have been replicated in this sample.

We acknowledge the fact that the measures of child and mother willing stance and of child outcomes were concurrent is a substantial, important limitation of the design and constrains inferences about developmental mediation. However, this limitation is likely offset, in part, by the benefits of the replication of Family Study findings in a demographically different sample. We controlled for assessments of both mediators and outcomes obtained prior to the studied sequence, whenever available; nevertheless, it is prudent to refer to the associations, rather than causal paths, between child and mother willing stance and the outcome measures.

\section{General Discussion}

In contrast to past views of socialization as a vaguely adversarial process, this work reflects a growing emphasis on positive collaboration between the parent and the child. This represents a shift from an earlier perspective-still common in research on behavior problems-that emphasized mostly children's resistance and opposition and parents' harsh and power-assertive discipline, and the resulting mutually coercive socialization cascades 
and maladaptive developmental outcomes. The findings affirm the heuristic and generative potential of attachment theory by demonstrating a key role of security in initiating positive socialization cascades that turn the socialization process into a mutually cooperative enterprise. Even if long-term, direct, main effects of attachment may no longer be present, early attachment is critical because of its role in the initiation of complex future sequelae; it is an organizing core in development, always integrated with later experience and never lost (Sroufe, 2005, 2016; Sroufe et al., 2005).

We argue that early security inaugurates a mutually collaborative parent-child partnership. The child adopts an eager, positive stance toward the parent, and becomes receptive to and willing to cooperate in the socialization process. The parent adopts an equally willing, supportive stance toward the child. This mutual positive stance has important implications for future developmental outcomes: It predicts few antisocial problems, a child's embrace of rules and standards for behavior, and a positive quality of the parent-child relationship. Although research has supported the path from early security to child cooperation to future developmental outcomes, much less is known about the path from security to parent cooperation to future outcomes. We tested both child and parent willing stance to each other as the mediators.

With only one exception (for mother-rated child antisocial problems at age 12), both studies produced consistent support for the first mediational path-from security to child willing stance to future outcomes. The findings were clear and replicated across the mother- and father-child relationships, across two demographically different samples (low-risk, twoparent community families and high-risk, diverse, low-income mothers), and across a range of outcomes in early adolescence and early school age. It was interesting that, whereas for mothers and children, the effects of security on the outcomes were all mediated only through the children's willing stance toward the mothers, with no significant effects mediated through the mother's willing stance, for fathers and children, the effects were mediated through both the children's and fathers' willing stance toward each other.

In almost all models where effects of security on the outcomes were found, they were fully accounted for by mediation through the child's, or the child's and the parent's, willing stance. One exception was the model for the effect of father-child security on father-child mutuality in the context of conflicts at age 12. In that model, toddler-age security also had a direct effect, over and above the effects mediated by the child's and the parent's willing stance. Given the lapse of 10 years between the assessment of security and negotiation of father-child conflict, this is an impressive finding, particularly in the context of generally modest long-term effects of early attachment reported in the literature. For father child dyads, early security appears to initiate a powerful positive cascade that encompasses indirect effects-through both partners' willing stance in early school age-on top of its continuing direct effect.

In the future, it will be important to address specific mechanisms that link security with the child's and/or parent's emerging willing stance. Positive affect may be one such mechanism (Dix, 1991; Lay, Waters, \& Park, 1989). As well, the child's emerging internal working model of the parent as responsive, trustworthy, and well intentioned, and the parent's 
internal working model of the child as cooperative and responsive may be key causal factors (Bugental \& Johnston, 2000; Dykas \& Cassidy, 2011; Grusec \& Goodnow, 1994; Kochanska \& Kim, 2012).

The multi-method multi-trait approach is a methodological strength of this work. The measures in both studies encompassed observations in many contexts and parents' reports using well-established instruments. The methodologies were purposely designed to be parallel across the two studies, in our effort to address the current concerns about replicability in social sciences. Note that the studies involved two distinct populations: a community sample of two-parent families and a diverse, exclusively low-income sample of mothers coping with limited resources and high adversity. Consequently, the findings can be generalized quite broadly.

We demonstrated that the child's eager, willing orientation toward the parent can be reliably coded in diverse interactive contexts, encompassing elicited imitation teaching tasks, freeflowing interactions, and parent-child discourse about past transgressions. Historically, all those contexts have been seen as important socialization venues, albeit in distinct traditions. Classic research on modeling emphasized imitation as a socialization mechanism (Bandura \& Walters, 1963). Reciprocity theories focused on social responsiveness in social interactions as a path to emerging sense of internal obligation (Parpal \& Maccoby, 1985; Reis, Clark, \& Holmes, 2004). The relatively recent approach integrating relationship and Vygotskian cultural learning perspectives has emphasized shared discourse and conversations as contexts for internalization (Laible, 2004; Laible \& Thompson, 2000; 2007; Thompson, 2013; 2015).

Differences in the sequelae of early attachment in mother- and father-child relationships were interesting. Although known, such differences are not yet well understood, with little consensus with regard to both antecedents and implications of mother-child and father-child security (Bretherton, 2010; Grossmann et al, 2002; Thompson, 2006). Future research on mother-child and father-child relationships, focused on links among early security, child and parent willing stance, and child outcomes, and incorporating a broad range of contexts within and outside of family environments, seems warranted.

This work has translational implications. Several parental interventions already encourage reinforcing child positive, cooperative behaviors, and instances when the child takes the lead in interaction in a non-adversarial fashion (Eyberg \& Bussing, 2010; McMahon \& Forehand, 2003; Webster-Stratton \& Reid, 2011). Although the term "willing stance" is not used, the current work suggests that it may be a key factor in reducing behavior problems; it also provides a conceptual framework in which to interpret the effects. Additionally, we elucidate early relational origins of child willing stance, highlighting the value of early intervention. Basic and translational research on child willing stance can substantially inform each other.

This work has limitations. The designs were not experimental, and as noted earlier, in Play Study the measures of children's and mothers' willing stance and the outcomes were all concurrent; thus, all inferences about the direction of effects are strongly limited. The overarching goal was to have fully parallel measures of children's willing stance across the 
two studies, at parallel ages (6.5 years in Family Study, 7 years in Play Study), and to extend the past work on earlier periods (Kochanska et al., 2015). Because the visit at age 7 was the last one in the Play Study, no later measures were available. However, the fact that we controlled for the measures of the outcomes, assessed concurrently to the mediators, and for the measures of mediators, assessed prior to security, reduced a probability of an alternative interpretation that the findings may be due to continuity of the parent's and child's characteristics.

As is often the case of research that aims to demonstrate a causal role of early attachment on future outcomes, alternative interpretations should be kept in mind. Early attachment quality may be just one marker of a positive parent-child relationship, or a marker of positive traits of both individuals. Attachment may therefore be, at least in part, an indicator of an adaptive trajectory, perhaps in addition to and/or instead of being its main cause.

Ideally, a full auto-regressive design would be the best approach to the study of child and parent reciprocal effects, unfolding over time. Unfortunately, our sample sizes, particularly in Family Study, were modest, and likely too small for such approach (Little, 2013). Future work with larger samples may allow for the implementation of such models.

Another limitation was the fact that the child's and parent's willing stance measures were not fully parallel. The child's willing stance was observed in discourse, teaching task, and a set of six naturalistic situations, and coded using three converging but different coding systems. The parent's willing stance was observed in the six naturalistic situations only (observations in the others contexts were available, but for fathers in Family Study, the three measures did not cohere). Perhaps this measurement discrepancy explains the relatively modest correlations between the child's and the parent's concurrent willing stance.

Psychologists' views on socialization have evolved substantially. The perspective that views socialization as a mutually cooperative enterprise is relatively recent. A worthy goal for developmental science is to understand better how positive cooperation emerges within the parent-child dyad, how it can be supported, and factors that promote or undermine it.

\section{Ethical approval}

All procedures performed in studies involving human participants were in accordance with the ethical standards of the institutional and/or national research committee and with the 1964 Helsinki declaration and its later amendments or comparable ethical standards.

\section{Informed consent}

Informed consent was obtained from all individual participants included in the study.

\section{Supplementary Material}

Refer to Web version on PubMed Central for supplementary material. 


\section{Acknowledgments}

This research was funded by NIMH Grants R01 MH63096 and K02 MH01446, NICHD Grant R01 HD069171, and a Stuit Professorship (to G.K.). We thank many colleagues, students and staff members for their help with data collection, coding, and file management, and parents and children in Family Study and Play Study for their commitment to this research.

\section{References}

Ainsworth, MDS., Bell, SM., Stayton, DJ. Individual differences in Strange Situation behavior of oneyear-olds. In: Schaffer, HR., editor. The origins of human social relations. London: Academic Press; 1971. p. 17-57.

Allen JP, McElhaney KB, Kuperminc GP, Jodl KM. Stability and change in attachment security across adolescence. Child Development. 2004; 75:1792-1805. DOI: 10.1111/j.1467-8624.2004.00817.x [PubMed: 15566380]

Allen JP, McElhaney KB, Land DJ, Kuperminc GP, Moore CW, O’Beirne-Kelly H, Liebman Kilmer S. A secure base in adolescence: Markers of attachment security in the mother-adolescent relationship. Child Development. 2003; 74:292-307. DOI: 10.1111/1467-8624.t01-1-00536 [PubMed: 12625451]

American Psychiatric Association. Diagnostic and statistical manual of mental disorders. 4. Washington, DC: American Psychiatric Press; 2000. text rev

Bandura, A., Walters, RH. Social learning and personality development. New York: Holt, Rinehart, and Winston; 1963.

Bates, JE., Schermerhorn, AC., Petersen, IT. Temperament and parenting in developmental perspective. In: Zentner, M., Shiner, R., editors. Handbook of temperament. New York: Guilford Press; 2012. p. 425-441.

Boldt LJ, Kochanska G, Yoon JE, Nordling JK. Children's attachment to both parents from toddler age to middle childhood: Links to adaptive and maladaptive outcomes. Attachment and Human Development. 2014; 16:211-229. DOI: 10.1080/14616734.2014.889181 [PubMed: 24605850]

Bowlby, J. Attachment and loss. 2. Vol. 1. New York: Basic Books; 1969/1982.

Bowlby, J. Attachment and loss. Vol. 2. New York: Basic Books; 1973.

Bradley RH, ... Corwyn RF. From parent to child to parent...: Paths in and out of problem behavior. Journal of Abnormal Child Psychology. 2013; 41:515-529. DOI: 10.1007/s10802-012-9692-x [PubMed: 23135289]

Bretherton I. Fathers in attachment theory and research: A review. Early Child Development and Care. 2010; 180:9-23. DOI: 10.1080/03004430903414661

Bretherton, I., Golby, B., Cho, E. Attachment and the transmission of values. In: Grusec, JE., Kuczynski, L., editors. Parenting and children's internalization of values: A handbook of contemporary theory. New York, NY: Wiley; 1997. p. 103-134.

Bugental DB, Johnston C. Parental and child cognitions in the context of the family. Annual Review of Psychology. 2000; 51:315-344. DOI: 10.1146/annurev.psych.51.1.315

Carter AS, Briggs-Gowan MJ, Jones SM, Little TD. The Infant-Toddler Social and Emotional Assessment (ITSEA): Factor structure, reliability, and validity. Journal of Abnormal Child Psychology. 2003; 31:495-514. DOI: 10.1023/A:1025449031360 [PubMed: 14561058]

Cassidy, J. The nature of the child's ties. In: Cassidy, J., Shaver, PR., editors. Handbook of attachment: Theory, research, and clinical applications. 2. New York, NY: Guilford; 2008. p. 3-22.

Clark MS. Record keeping in two types of relationships. Journal of Personality and Social Psychology. 1984; 47:549-557. DOI: 10.1037/0022-3514.47.3.549 [PubMed: 6491869]

Cole DA, Maxwell SE. Testing mediational models with longitudinal data: Questions and tips in the use of structural equation modeling. Journal of Abnormal Psychology. 2003; 112:558-577. DOI: 10.1037/0021-843X.112.4.558 [PubMed: 14674869]

Dadds MR, Salmon K. Punishment insensitivity and parenting: Temperament and learning as interacting risks for antisocial behavior. Clinical Child and Family Psychology Review. 2003; 6:69-86. DOI: 10.1023/A:1023762009877 [PubMed: 12836578] 
Dishion, TJ., Patterson, GR. The development and ecology of antisocial behavior in children and adolescents. In: Cicchetti, D., Cohen, DJ., editors. Developmental psychopathology. 2. Vol. 3. Hoboken, NJ: Wiley; 2006. p. 503-541.

Dix T. The affective organization of parenting: Adaptive and maladaptive processes. Psychological Bulletin. 1991; 110:3-25. [PubMed: 1891517]

Dykas MJ, Cassidy J. Attachment and the processing of social information across the life span: Theory and evidence. Psychological Bulletin. 2011; 137:19-46. DOI: 10.1037/a0021367 [PubMed: 21219056]

Eisenberg N, Guthrie IK, Fabes RA, Shepard S, Losoya S, Murphy B, ... Reiser M. Prediction of elementary school children's externalizing problem behaviors from attentional and behavioral regulation and negative emotionality. Child Development. 2000; 71:1367-1382. DOI: 10.1111/1467-8624.00233 [PubMed: 11108101]

Essex MJ, Boyce WT, Goldstein LH, Armstrong JM, Kraemer HC, Kupfer DJ. The confluence of mental, physical, social and academic difficulties in middle childhood. II: Developing the MacArthur Health and Behavior Questionnaire. Journal of the American Academy of Child \& Adolescent Psychiatry. 2002; 41:588-603. DOI: 10.1097/00004583-200205000-00017 [PubMed: 12014792]

Eyberg, SM., Bussing, R. Parent-child interaction therapy for preschool children with conduct problems. In: Murrihy, RC.Kidman, AD., Ollendick, TH., editors. Clinical handbook of assessing and treating conduct problems in youth. New York: Springer; 2010. p. 139-162.

Gadow, KD., Sprafkin, J. Child Symptom Inventory-4: Screening and Norms Manual. Stony Brook, NY: Checkmate Plus; 2002.

Gadow, KD., Sprafkin, J. Adolescent Symptom Inventory-4 Consolidated Manual. Stony Brook, NY: Checkmate Plus; 2008.

Gardner F, Burton J, Klimes I. Randomised controlled trial of a parenting intervention in the voluntary sector for reducing child conduct problems: outcomes and mechanisms of change. Journal of Child Psychology and Psychiatry. 2006; 47:1123-1132. DOI: 10.1111/j.1469-7610.2006.01668.x [PubMed: 17076751]

Grossmann K, Grossmann KE, Fremmer-Bombik E, Kindler H, Scheuerer-Englisch H, Zimmermann $\mathrm{P}$. The uniqueness of the child-father attachment relationship: Fathers' sensitive and challenging play as a pivotal variable in a 16-year longitudinal study. Social Development. 2002; 11:307-331. DOI: $10.1111 / 1467-9507.00202$

Grusec JE, Goodnow JJ. Impact of parental discipline methods on the child's internalization of values: A reconceptualization of current points of view. Developmental Psychology. 1994; 30:4-19. DOI: 10.1037/0012-1649.30.1.4

Hawes DJ, Dadds MR, Frost ADJ, Hasking PA. Do childhood callous-unemotional traits drive change in parenting practices? Journal of Clinical Child \& Adolescent Psychology. 2011; 40:507-518. DOI: 10.1080/15374416.2011.581624 [PubMed: 21722024]

Hayes, A. Introduction to mediation, moderation, and conditional process analysis: A regression-based approach. New York: Guilford Press; 2013.

Hoeve M, Stams GJJM, van der Put CE, Dubas JS, van der Laan PH, Gerris JRM. A meta-analysis of attachment to parents and delinquency. Journal of Abnormal Child Psychology. 2012; 40:771-785. DOI: 10.1007/s10802-011-9608-1 [PubMed: 22278802]

Hoyle, RH., Robinson, JI. Mediated and moderated effects in social psychological research: Measurement, design, and analysis issues. In: Sansone, C.Morf, CC., Panter, AT., editors. Handbook of methods in social psychology. Thousand Oaks, CA: Sage; 2003. p. 213-233.

Kochanska G, Aksan N, Carlson JJ. Temperament, relationships, and young children's receptive cooperation with their parents. Developmental Psychology. 2005; 41:648-660. [PubMed: 16060811]

Kochanska G, Coy KC, Murray KT. The development of self-regulation in the first four years of life. Child Development. 2001; 72:1091-1111. DOI: 10.1111/1467-8624.00336 [PubMed: 11480936]

Kochanska G, Kim S. Toward a new understanding of legacy of early attachments for future antisocial trajectories: Evidence from two longitudinal studies. Development and Psychopathology. 2012; 24:783-806. DOI: 10.1017/S0954579412000375 [PubMed: 22781855] 
Kochanska G, Kim S. A complex interplay among the parent-child relationship, effortful control, and internalized, rule-compatible conduct in young children: Evidence from two studies. Developmental Psychology. 2014; 50:8-21. DOI: 10.1037/a0032330 [PubMed: 23527491]

Kochanska G, Kim S, Boldt LJ. Origins of children's externalizing behavior problems in low-income families: Toddlers' willing stance toward their mothers as the missing link. Development and Psychopathology. 2013a; 25:891-901. DOI: 10.1017/S0954579413000254 [PubMed: 24229537]

Kochanska G, Kim S, Boldt LJ. (Positive) power to the child: The role of children's willing stance toward parents in developmental cascades from toddler age to early preadolescence. Development and Psychopathology. 2015; 27:987-1005. DOI: 10.1017/S0954579415000644 [PubMed: 26439058]

Kochanska G, Kim S, Boldt LJ, Nordling JK. Promoting toddlers' positive social-emotional outcomes in low-income families: A play-based experimental study. Journal of Clinical Child and Adolescent Psychology. 2013b; 42:700-712. DOI: 10.1080/15374416.2013.782815 [PubMed: 23557253]

Kochanska G, Koenig JL, Barry RA, Kim S, Yoon JE. Children's conscience during toddler and preschool years, moral self, and a competent, adaptive developmental trajectory. Developmental Psychology. 2010a; 46:1320-1332. DOI: 10.1037/a0020381 [PubMed: 20822241]

Kochanska G, Woodard J, Kim S, Koenig JL, Yoon JE, Barry RA. Positive socialization mechanisms in secure and insecure parent-child dyads: Two longitudinal studies. Journal of Child Psychology and Psychiatry. 2010b; 51:998-1009. DOI: 10.1111/j.1469-7610.2010.02238.x [PubMed: 20406336]

Laible DJ. Mother-child discourse surrounding a child's past behavior at 30 months: Links to emotional understanding and early conscience development at 36 months. Merrill-Palmer Quarterly. 2004; 50:159-180. DOI: 10.1353/mpq.2004.0013

Laible DJ, Thompson RA. Mother-child discourse, attachment security, shared positive affect, and early conscience development. Child Development. 2000; 71:1424-1440. DOI: 10.1111/1467-8624.00237 [PubMed: 11108105]

Laible, DJ., Thompson, RA. Early socialization: A relationship perspective. In: Grusec, JE., Hastings, PD., editors. Handbook of socialization: Theory and research. New York, NY: Guilford Press; 2007. p. 181-207.

Lay KL, Waters E, Park KA. Maternal responsiveness and child compliance: The role of mood as mediator. Child Development. 1989; 60:1405-1411. DOI: 10.2307/1130930 [PubMed: 2612249]

Lipscomb ST, Leve LD, Harold GT, Neiderhiser JM, Shaw DS, Ge X, Reiss D. Trajectories of parenting and child negative emotionality during infancy and toddlerhood: A longitudinal analysis. Child Development. 2011; 82:1661-1675. DOI: 10.1111/j.1467-8624.2011.01639.x [PubMed: 21883160]

Little RJA. A test of missing completely at random for multivariate data with missing values. Journal of the American Statistical Association. 1988; 83:1198-1202. DOI: 10.1080/01621459.1988.10478722

Little, TD. Longitudinal structural equation modeling. New York: Guilford Press; 2013.

Londerville S, Main M. Security of attachment, compliance, and maternal training methods in the second year of life. Developmental Psychology. 1981; 17:289-299. DOI: 10.1037/0012-1649.17.3.289

Lorber MF, Egeland B. Parenting and infant difficulty: Testing a mutual exacerbation hypothesis to predict early onset conduct problems. Child Development. 2011; 82:2006-2020. DOI: 10.1111/j. 1467-8624.2011.01652.x [PubMed: 22026438]

Maccoby EE. The role of parents in the socialization of children: An historical overview. Developmental Psychology. 1992; 28:1006-1017. DOI: 10.1037/0012-1649.28.6.1006

MacKinnon DP, Lockwood CM, Williams J. Confidence limits for the indirect effect: Distribution of the product and resampling methods. Multivariate Behavioral Research. 2004; 39:99-128. DOI: 10.1207/s15327906mbr3901_4 [PubMed: 20157642]

Marvin, RS., Britner, PA., Russell, BS. Normative development: The ontogeny of attachment in childhood. In: Cassidy, J., Shaver, PR., editors. Handbook of attachment: Theory, research and clinical applications. 3. New York: Guilford Publications; 2016. p. 273-290. 
Matas L, Arend RA, Sroufe LA. Continuity of adaptation in the second year: The relationship between quality of attachment and later competence. Child Development. 1978; 49:547-556. DOI: $10.2307 / 1128221$

McMahon, RJ., Forehand, R. Helping the noncompliant child: A clinician's guide to effective parent training. New York: Guilford Press; 2003.

Pardini DA. Novel insights into longstanding theories of bidirectional parent-child influences: Introduction to the special section. Journal of Abnormal Child Psychology. 2008; 36:627-631. DOI: 10.1007/s10802-008-9231-y [PubMed: 18437550]

Pardini, DA., Waller, R., Hawes, SW. Familial influences on the development of serious conduct problems and delinquency. In: Morizot, J., Kazemian, L., editors. The Development of Criminal and Antisocial Behavior: Theory, Research and Practical Applications. New York: Springer International Publishing; 2015. p. 201-220.

Parpal M, Maccoby EE. Maternal responsiveness and subsequent child compliance. Child Development. 1985; 56:1326-1334. DOI: 10.2307/1130247

Pasalich DS, Dadds MR, Hawes DJ, Brennan J. Attachment and callous-unemotional traits in children with early-onset conduct problems. Journal of Child Psychology and Psychiatry. 2012; 53:838845. DOI: 10.1111/j.1469-7610.2012.02544.x [PubMed: 22394435]

Patterson GR, DeBaryshe BD, Ramsey E. A developmental perspective on antisocial behavior. American Psychologist. 1989; 44:329-335. DOI: 10.1037/0003-066X.44.2.329 [PubMed: 2653143]

Pettit GS, Arsiwalla DD. Commentary on special section on "Bidirectional parent-child relationships": The continuing evolution of dynamic, transactional models of parenting and youth behavior problems. Journal of Abnormal Child Psychology. 2008; 36:711-718. DOI: 10.1007/ s10802-008-9242-8 [PubMed: 18473161]

Preacher KJ, Hayes AF. SPSS and SAS procedures for estimating indirect effects in simple mediation models. Behavior Research Methods, Instruments, \& Computers. 2004; 36:717-731. DOI: 10.3758/BF03206553

Reid JB, Patterson GR. The development of antisocial behaviour patterns in childhood and adolescence. European Journal of Personality. 1989; 3:107-119. DOI: 10.1002/per.2410030205

Reis, HT., Clark, MS., Holmes, JG. Perceived partner responsiveness as an organizing construct in the study of intimacy and closeness. In: Mashek, D., Aron, A., editors. The handbook of closeness and intimacy. Mahwah, NJ: Lawrence Erlbaum Associates; 2004. p. 201-225.

Rushton JP, Brainerd CJ, Pressley M. Behavioral development and construct validity: the principle of aggregation. Psychological Bulletin. 1983; 94:18-38. DOI: 10.1037/0033-2909.94.1.18

Shaver, PR., Mikulincer, M., Gross, JT., Stern, JA., Cassidy, J. A lifespan perspective on attachment and care for others. In: Cassidy, J., Shaver, PR., editors. Handbook of attachment: Theory, research and clinical applications. 3. New York: Guilford Publications; 2016. p. 878-916.

Shaw DS. Innovative approaches and methods to the study of children's conduct problems. Social Development. 2003; 12:309-313. DOI: 10.1111/1467-9507.00235

Shaw DS, Bell RQ. Developmental theories of parental contributors to antisocial behavior. Journal of Abnormal Child Psychology. 1993; 21:493-518. DOI: 10.1007/BF00916316 [PubMed: 8294650]

Smith JD, Dishion TJ, Shaw DS, Wilson MN, Winter CC, Patterson GR. Coercive family process and early-onset conduct problems from age 2 to school entry. Development and Psychopathology. 2014; 26:917-932. DOI: 10.1017/S0954579414000169 [PubMed: 24690305]

Sroufe LA. Attachment and development: A prospective, longitudinal study from birth to adulthood. Attachment \& Human Development. 2005; 7:349-367. [PubMed: 16332580]

Sroufe, LA. The place of attachment in development. In: Cassidy, J., Shaver, PR., editors. Handbook of attachment: Theory, research and clinical applications. 3. New York: Guilford Publications; 2016. p. 997-1011.

Sroufe, LA., Egeland, B., Carlson, EA., Collins, WA. The development of the person: The Minnesota study of risk and adaptation from birth to adulthood. New York, NY: Guilford Publications; 2005.

Thompson, RA. The development of the person: Social understanding, relationships, conscience, self. In: Damon, W.Lerner, RM., Eisenberg, N., editors. Handbook of child psychology: Social, emotional, and personality development. Vol. 3. New York, NY: Wiley; 2006. p. 24-98. 
Thompson, RA. Conscience development in early childhood. In: Killen, M., Smetana, J., editors. Handbook of moral development. 2. New York, NY: Taylor \& Francis; 2013. p. 73-92.

Thompson, RA. Relationships, regulation, and early development. In: Lamb, ME., Garcia Coll, C., editors. Social, emotional, and personality development: Vol. 3. Handbook of child psychology and developmental science. 7. Hoboken, NJ: Wiley; 2015. p. 201-246.

Thompson, RA. Early attachment and later development: Reframing the questions. In: Cassidy, J., Shaver, PR., editors. Handbook of attachment: Theory, research, and clinical applications. 3. New York: Guilford Press; 2016. p. 330-348.

van IJzendoorn MH. Attachment, emergent morality, and aggression: Toward a developmental socioemotional model of antisocial behaviour. International Journal of Behavioral Development. 1997; 21:703-728. DOI: 10.1080/016502597384631

Waters, E. Attachment Behavior Q-Set. State University of New York at Stony Brook, Department of Psychology; 1987. (Revision 3.0) Unpublished instrument

Waters E, Deane K. Defining and assessing individual differences in attachment relationships: Qmethodology and the organization of behavior in infancy and early childhood. Monographs of the Society for Research in the Child Development. 1985; 50:41-65. DOI: 10.2307/3333826

Waters, E., Kondo-Ikemura, K., Posada, G., Richters, JE. Learning to love: Mechanisms and milestones. In: Gunnar, M., Sroufe, LA., editors. Minnesota symposia on child psychology. Vol. 23. Hillsdale, NJ: Erlbaum; 1990. p. 217-255.

Webster-Stratton, C., Reid, MJ. The Incredible Years program for children from infancy to preadolescence: Prevention and treatment of behavior problems. In: Murrihy, RC.Kidman, AD., Ollendick, TH., editors. Clinical handbook of assessing and treating conduct problems in youth. New York: Springer; 2011. p. 117-138. 
Indirect Effect

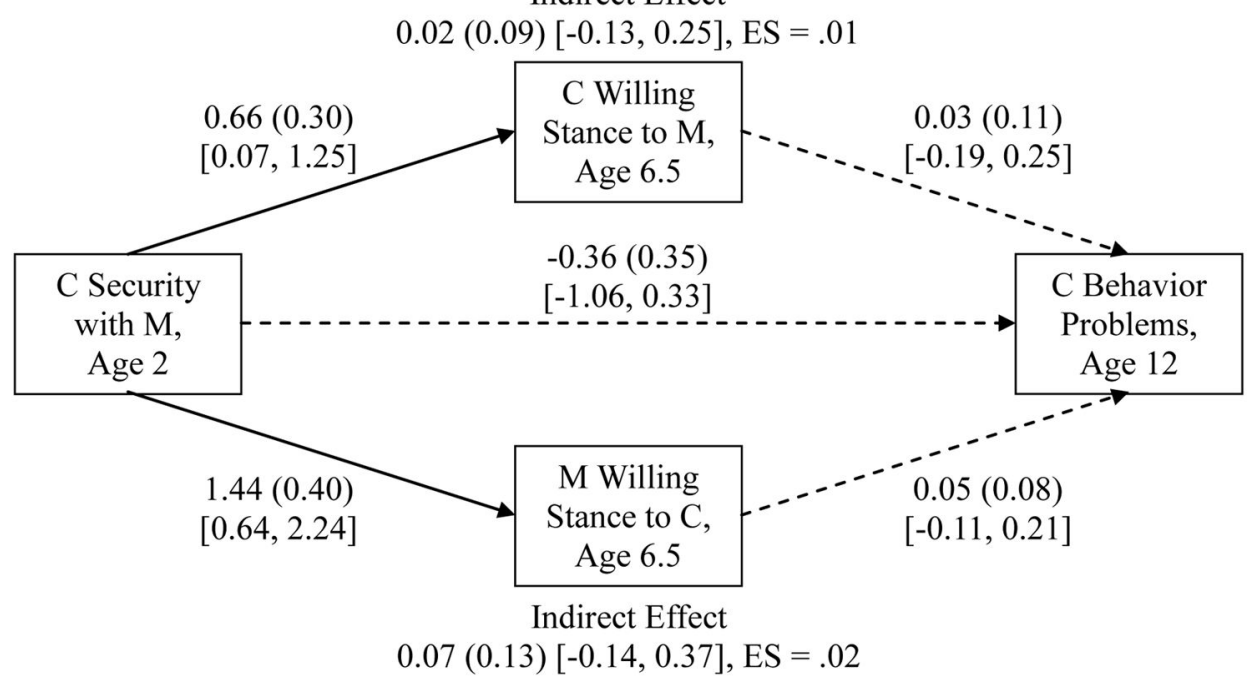

Indirect Effect

$0.23(0.13)[0.05,0.58], \mathrm{ES}=.08$

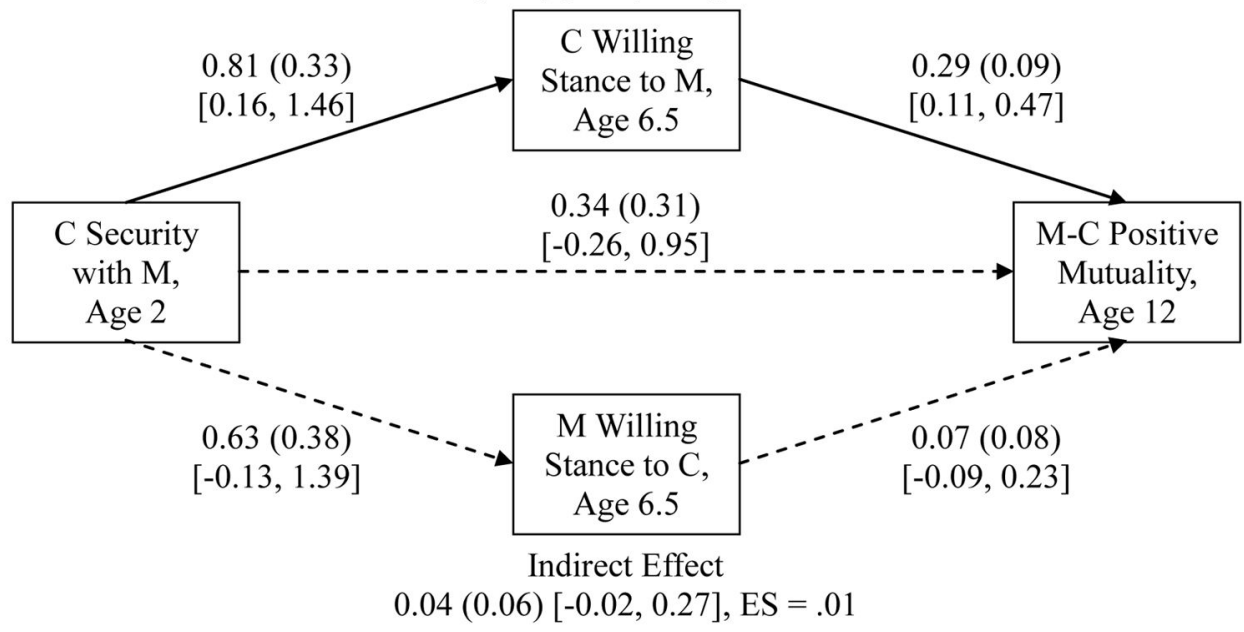

Figure 1.

Family Study, mother-child dyads. Mediation model: From child security to child and mother willing stance to developmental outcomes. Reported unstandardized coefficients, standard errors (in parentheses), bootstrap 95\% CIs [in brackets], and completely standardized indirect effect size (ES). Solid lines represent significant effects; dashed lines represent non-significant effects. $\mathrm{M}=$ Mother, $\mathrm{C}=$ Child. Significant indirect effects are bolded. Covariates include child gender, antecedents of age 12 outcomes (measured at 6.5 years), and antecedents of age 6.5 mediators (measured in infancy), but are not depicted. 

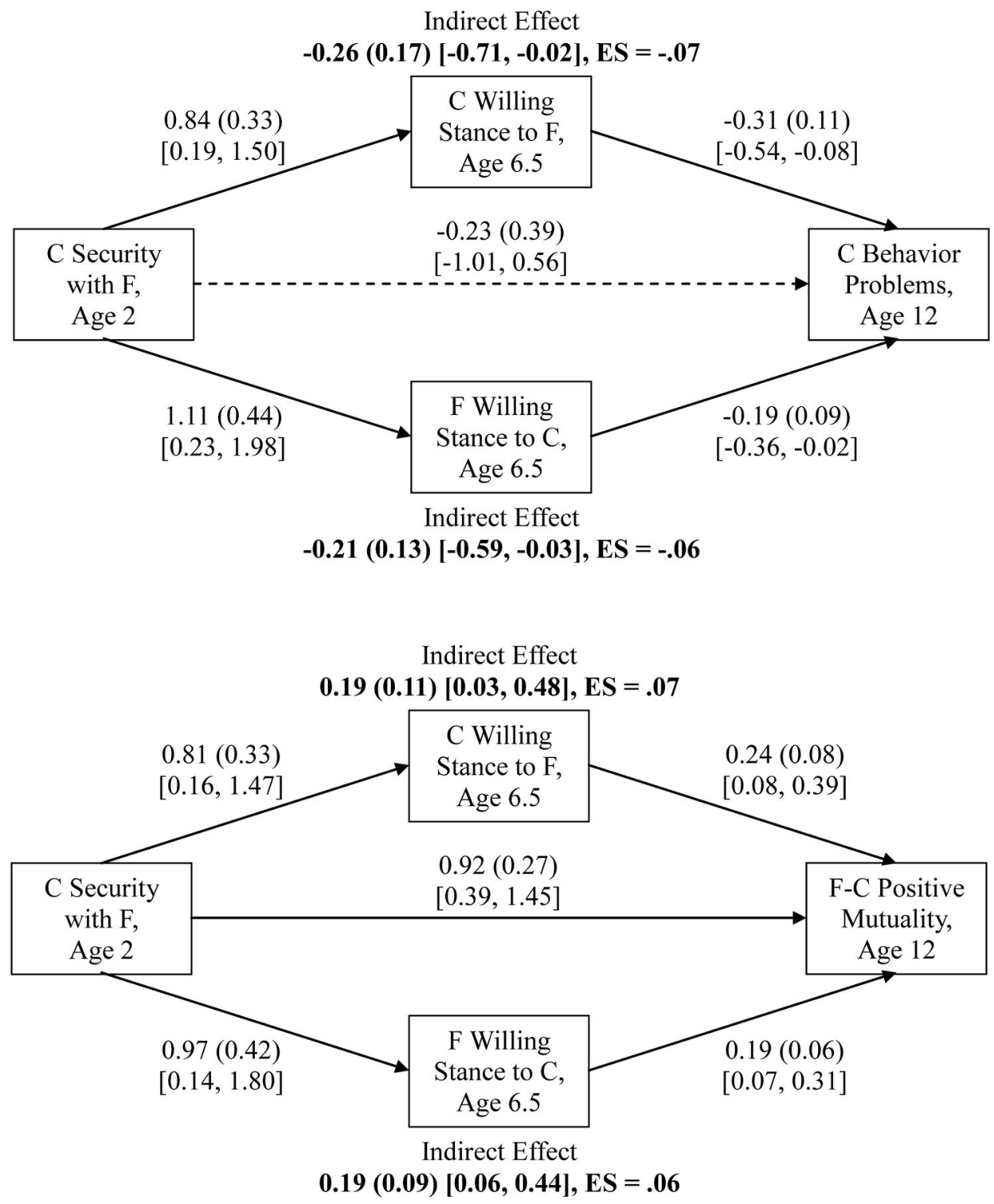

Figure 2.

Family Study, father-child dyads. Mediation model: From child security to child and father willing stance to developmental outcomes. Reported unstandardized coefficients, standard errors (in parentheses), bootstrap 95\% CIs [in brackets], and completely standardized indirect effect size (ES). Solid lines represent significant effects; dashed lines represent nonsignificant effects. $\mathrm{F}=$ Father, $\mathrm{C}=$ Child. Significant indirect effects are bolded. Covariates include child gender, antecedents of age 12 outcomes (measured at 6.5 years), and antecedents of age 6.5 mediators (measured in infancy), but are not depicted. 

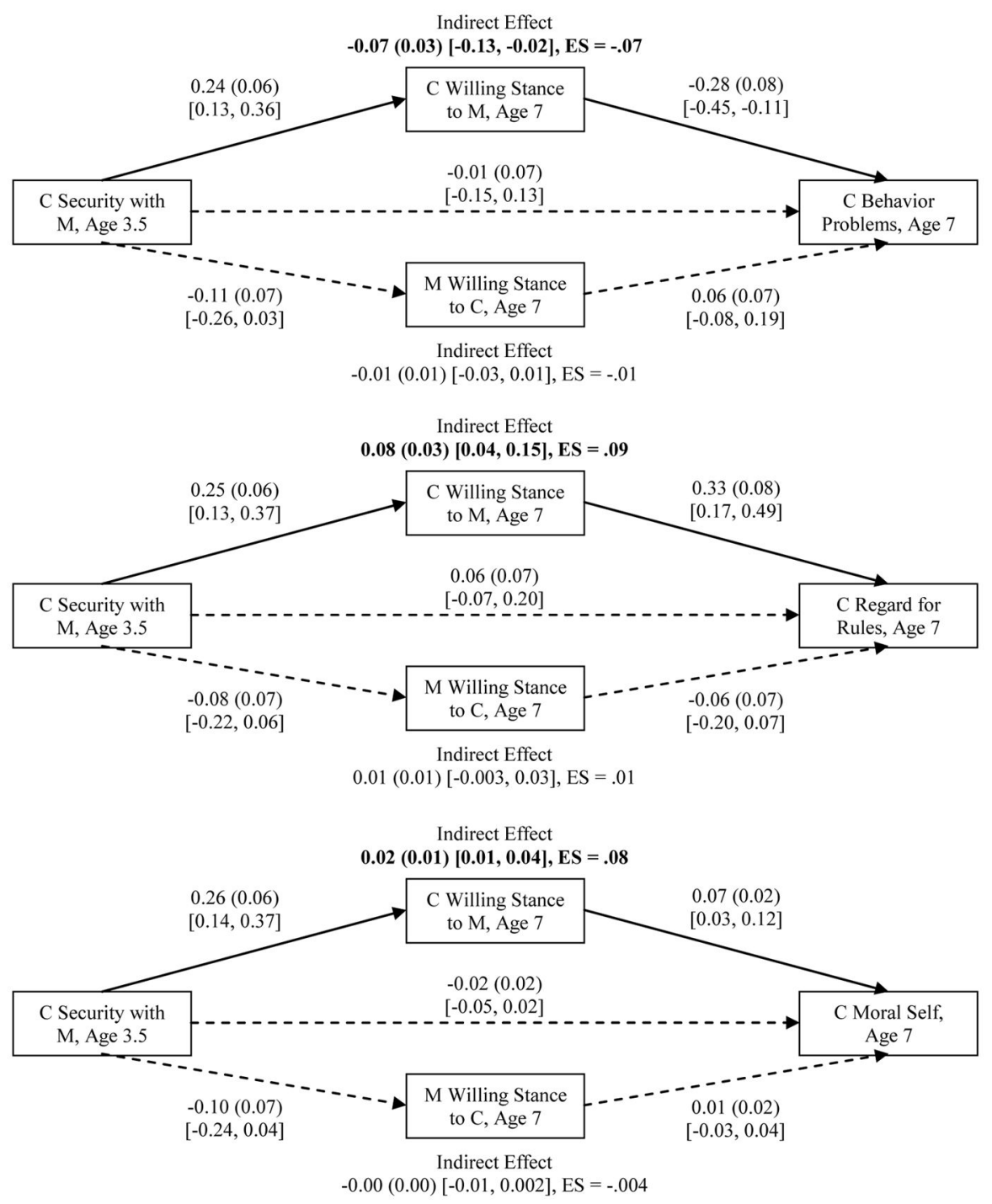

Figure 3.

Play Study, mother-child dyads. Mediation model: From child security to child and mother willing stance to developmental outcomes. Reported unstandardized coefficients, standard errors (in parentheses), bootstrap 95\% CIs [in brackets], and completely standardized indirect effect size (ES). Solid lines represent significant effects; dashed lines represent nonsignificant effects. $\mathrm{M}=$ Mother, $\mathrm{C}=$ Child. Significant indirect effects are bolded. Covariates include child gender, group assignment, and antecedents (measured at 2.5 years) of outcomes and mediators (measured at 7 years), but are not depicted. 